\title{
Enhanced Visual Search for a Conjunctive Target in Autism: A Research Note
}

\author{
Kate Plaisted, Michelle O'Riordan, and Simon Baron-Cohen \\ University of Cambridge, U.K.
}

\begin{abstract}
Children with and without autism were compared on two visual search tasks in which a letter target appeared among two sets of letter distracters. In one task, the target shared colour with one set of distracters but was unique in shape - the feature search task. In the other, the conjunctive search task, the target shared colour with one set and shape with another set of distracters. Although search was slower in the conjunctive task than the feature task in normally developing control children, children with autism showed no significant slowing in reaction time in the conjunctive task and were faster than control children in this task. This result is discussed in the light of theories of visual search which state that rate of search is determined by the degree of similarity between target and distracters.
\end{abstract}

Keywords: Autism, attention, conjunctive search, feature search.

\section{Introduction}

Attentional abnormalities in autism have been widely documented and commented upon, from Kanner's original description of the disorder (Kanner, 1943) to reports by clinicians and educators (e.g. National Society for Autistic Children, 1978; Hayes, 1987). For example, children with autism often actively avoid certain stimuli in their environments (often loud or changing stimuli) and seek out others (often highly predictable stimuli). Furthermore, it is frequently reported anecdotally that preferred stimuli trigger periods of obsessive attentional focus, to the exclusion of other stimuli, even when these others are perceptually salient.

In general, experimental studies have found empirical support for attentional deficits in autism. For example, Courchesne and his colleagues (Courchesne, Townsend, Ashoomoff, Yeung-Courchesne et al., 1994; Courchesne, Townsend, Ashoomoff, Saitoh, et al., 1994) have found that the performance of individuals with autism was slower than a control group on tasks that required rapid attentional shifts between different stimuli, either within the same modality or between modalities. Furthermore, Wainwright and Bryson (1996) found that highfunctioning adults with autism and Asperger's syndrome were slower to orient to peripherally presented stimuli than were matched control adults. Similarly, individuals with autism have been shown to be slower to detect a target in cueing tasks where the target is overtly cued (Townsend, Courchesne, \& Egaas, 1996) or overtly cued (Wainwright-Sharpe \& Bryson, 1993) in Posner-type cueing tasks (Posner, 1980). These findings are therefore

Requests for reprints to: K. C. Plaisted, Department of Experimental Psychology, University of Cambridge, Downing Site, Cambridge CB2 3EB, U.K. (E-mail: kcp1000@cus.cam.ac.uk). consistent with anecdotal observations of abnormal attentional focus in autism, because it is conceivable that slower attention shifting could result in overselective attention.

However, these findings are in marked contrast to the faster performance of individuals with autism on tasks such as the block design subtest of the Wechsler intelligence scales (Shah \& Frith, 1993) and faster and more accurate performance on the embedded figures task (Jolliffe \& Baron-Cohen, 1997; Shah \& Frith, 1983), compared to matched control groups. Furthermore, we have recently found that individuals with autism discriminate better between novel, highly similar stimuli in a perceptual learning task than do a matched control group (Plaisted, O'Riordan, \& Baron-Cohen, 1998). All three tasks require item detection - the appropriate block face for part of a design in the block design subtest, the "hidden" figure in the embedded figures task, and the unique features of each stimulus in the discrimination task - and therefore rapid scanning of the stimuli involved in each task. This presumably involves shifting visual attention between different parts of the visual array.

These demonstrations of superior item detection are clearly at odds with the idea that visual orienting and attentional switching is slower in autism. Of course, it is more than likely that processing differences in domains other than visual attention underlie the superior performance of individuals with autism on the block design, embedded figures, and discrimination tasks (e.g. weak central coherence, Frith, 1989; reduced generalisation of responding, Plaisted et al., 1998). These processes may operate with such efficiency in autism that they offset any impact on performance of slowed attention shifting. Alternatively, there may be differences in terms of which processes of visual attention are engaged in different tasks. This raises the possibility that individuals with 

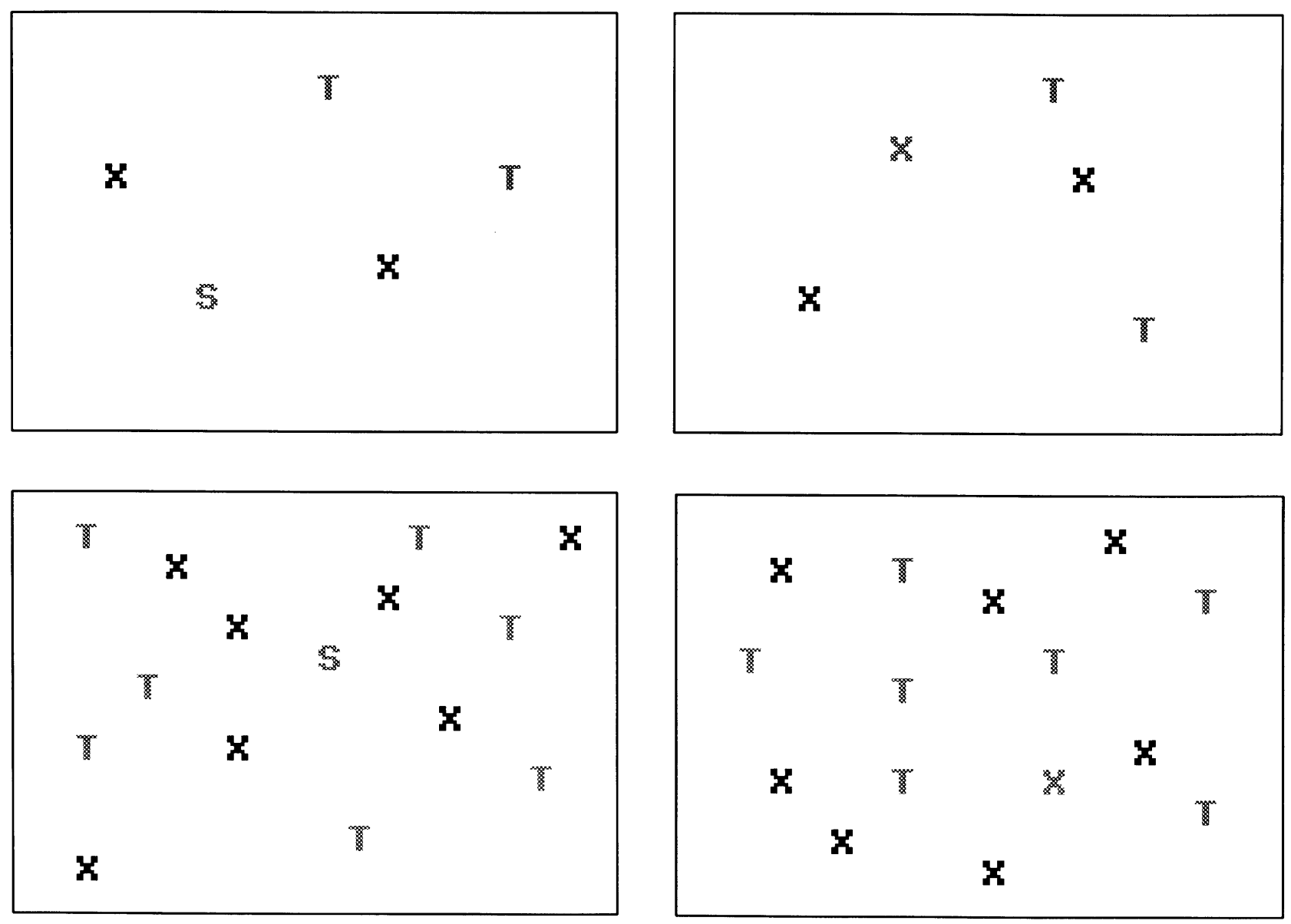

Figure 1. Examples of disjunctive and conjunctive search tasks. The top panels show 5-item displays and the bottom panels show 15-item displays. The left panels illustrate a feature search task, in which the target (grey S) shares colour with one set of distracters (grey Ts). The right panels illustrate a conjunctive search target in which the target (grey X) shares colour with one set of distracters (grey Ts) and shape with the other set (black Xs).

autism will show poor performance on some attentional tasks but comparable or even superior performance compared to control groups on others.

One task in which we felt individuals with autism might show comparable or superior performance is visual search. Visual search tasks typically involve searching for a target letter when it is presented among several distracter letters. Figure 1 gives examples of such tasks. In one condition (feature search) the target might share one dimension, such as colour, with one set of distracters and be unique in another dimension, such as form (e.g. searching for a red $\mathrm{S}$ among red $\mathrm{T}$ and green $\mathrm{X}$ distracters - see the two left panels of Fig. 1). Hence, the feature target is uniquely defined by one dimension. In another condition (conjunctive search) the target might share one dimension with one set and another dimension with the other set of distracters (e.g. searching for a red X among red $\mathrm{T}$ and green $\mathrm{X}$ distracters - the two right panels of Fig. 1). Hence, the conjunctive target is defined by a unique combination or conjunction of two dimensions. A classic finding in normal individuals is that target detection time increases linearly with increases in the number of distracters in conjunctive search tasks but does not increase at larger display sizes in feature search tasks (Duncan \& Humphries, 1989; Treisman \& Gelade, 1980; Wolfe, Cave, \& Franzel, 1989).
We predicted that individuals with autism would show faster target detection in visual search tasks than normal individuals for two reasons. (Although we predicted faster target detection in both tasks, we did not expect to obtain an empirical difference between the groups in the feature search task, because performance by the control group was expected to be at ceiling. Hence, the empirical difference between groups was specifically predicted for the conjunctive search task.) The first reason follows from speculations about the nature of the embedded figures and discrimination tasks. Both can be said to involve a discrimination of relevant items from nonrelevant items on the basis of the unique aspects of those items. This is also the case for the feature and conjunctive search tasks, because the targets are, in certain respects, different from the distracters in each task. In short, individuals with autism may be extremely good at "odd man out" tasks.

The second reason relates to an analysis of the embedded figures task. This task requires the detection of a hidden figure when it is embedded within a larger picture or figure. That is, the picture is composed of a set of different shapes and the target can be considered as a subset of those shapes. In addition, the target shares part of its shape with some distracter shapes in the picture and the rest of its shape with other distracters. Hence, the 
target is a unique combination or integration of shapes present throughout the picture. The embedded figures task can therefore be thought of as a within-dimension conjunctive search task. If this task analysis is correct, the prediction is that children with autism will be better than control children on any conjunctive search task. The current study therefore compared the performance of a group of children with autism and developmentally normal children on two search tasks, one for a conjunctive target and one for a feature target.

\section{Method}

\section{Participants}

Two groups of children participated: a group of eight children with autism and a control group of eight developmentally normal children. These sample sizes are standard in experiments involving visual search tasks. All children in the group with autism had been diagnosed by clinicians according to criteria such as those specified in DSM-IV (American Psychiatric Association, 1994). The ages of the children with autism ranged from 7 years to 10 years 1 month. The ages of the control children ranged from 6 years 6 months to 9 years 1 month. Developmental studies of conjunctive and disjunctive visual search have established that infants show the same pattern of visual search as adults (Gerhardstein, 1997). The children with autism were recruited via the National Autistic Society and children in the control group were recruited via local primary schools. The children were assessed for verbal mental age (verbal MA) using the British Picture Vocabulary Scale (BPVS) Long Form (Dunn, Dunn, Whetton, \& Pintile, 1982) and for spatial mental age (spatial MA) using the WISC-R block design subtest (Wechsler, 1976). Unpaired $t$-tests revealed that the chronological ages and BPVS scores of the two groups of children did not differ $[t(14)=1.74, p>.1$, and $t(14)=0.2$, $p>.8$, respectively]. An unpaired $t$-test of the block design subtest scores revealed that the children with autism performed significantly better than the developmentally normal children $[t(14)=3.36, p<.05]$. The means, standard deviations, and range in years and months for chronological age, BPVS, and block design are presented in Table 1. No developmentally delayed control group was included as the prediction was that the performance of the group with autism would be superior to that of the normal group.

\section{Stimuli and Apparatus}

Stimulus displays consisted of 5,15 , or 25 letter characters arranged in an imaginary $16.8 \mathrm{~cm} \times 16.8 \mathrm{~cm}$ grid of approximately 33 degrees of visual angle, centred around a central fixation point. Each letter measured $0.5 \mathrm{~cm} \times 0.5 \mathrm{~cm}$, sub- tending approximately 1.0 degree of visual angle horizontally and 1.0 degree vertically. The minimum distances between letters in any display were $0.7 \mathrm{~cm}$ between positions in a row and $0.7 \mathrm{~cm}$ between positions in a column. Display size refers to the number of letters in the display, not to the physical boundaries of the display, which remained fixed. Display letters comprised two dimensions: colour (red and green) and form (S, $\mathrm{T}$, and $\mathrm{X}$ )

The stimuli were generated by an Acorn Risc PC computer and displayed on a 14-inch colour monitor. Children responded by pressing one of two keys on the keyboard (the "." key with the right hand or the " $z$ " key with the left hand). In order to prevent other keys being pressed, the keyboard was covered by a hard black plastic cover, which had two openings to allow access to the response keys.

\section{Procedure}

There were two conditions. In one, children searched for a feature target that shared colour with one kind of distracter but was unique in terms of shape - a red $\mathrm{S}$ target among red $\mathrm{T}$ and green $\mathrm{X}$ distracters. In the other, children searched for a conjunction target that shared colour with one type of distracter and form with the other - a red $\mathrm{X}$ among green $\mathrm{X}$ and red $\mathrm{T}$ distracters. There were a total of 60 test trials per condition and each condition contained 2 crossed factors: display size (5, 15, and 25 letters), and probe (target present, target absent). There were equal numbers of target present and target absent trials and equal numbers of trials of the three display sizes.

Each child received each condition in different sessions and sessions were separated by a minimum of 2 hours. Half the children in each group received the feature search condition in their first session and the conjunction search condition in their second session. The remaining children received the two conditions in the reverse order. Prior to the start of each session, children were informed that their task was to look for a particular target (a red S or a red X) and to ignore any other letters that might appear. They were told to press the " $\mathrm{z}$ " key (verbally labelled the "YES" key) if they found the target and the "." key (verbally labelled the "NO" key) if they could not find the target. Children were instructed to respond as quickly as possible with as few mistakes as possible. There then followed 12 practice trials. As in the test trials, there were equal numbers of target present and target absent trials and equal numbers of trials of the three display sizes. Throughout the session, prior to each trial, a fixation point (a white hash) was presented for $500 \mathrm{msec}$ at the centre of the screen, after which it was immediately replaced by presentation of the display. The display remained in view until the child responded and a black screen

Table 1

Subject Characteristics

\begin{tabular}{|c|c|c|c|c|c|c|}
\hline \multirow[b]{2}{*}{ Group } & & \multirow[b]{2}{*}{ Age $(y: m)$} & \multicolumn{2}{|c|}{ British Picture Vocabulary Scale } & \multicolumn{2}{|c|}{ Block design subtest ${ }^{\mathrm{a}}$} \\
\hline & & & Verbal MA & $\begin{array}{l}\text { Standardised } \\
\text { scores }\end{array}$ & Spatial MA & $\begin{array}{l}\text { Scaled } \\
\text { scores }\end{array}$ \\
\hline $\begin{array}{l}\text { Autism } \\
(N=8)\end{array}$ & $\begin{array}{l}\text { Mean } \\
S D \\
\text { Range }\end{array}$ & $\begin{array}{c}8: 9 \\
1: 2 \\
7: 0-10: 1\end{array}$ & $\begin{array}{c}6: 10 \\
2: 0 \\
4: 6-9: 0\end{array}$ & $\begin{array}{l}81.7 \\
22.95 \\
66-88\end{array}$ & $\begin{array}{c}11: 5 \\
3: 6 \\
7: 6-16: 10\end{array}$ & $\begin{array}{c}12.9 \\
3.5 \\
7-17\end{array}$ \\
\hline $\begin{array}{l}\text { Normal } \\
(N=8)\end{array}$ & $\begin{array}{l}\text { Mean } \\
S D \\
\text { Range }\end{array}$ & $\begin{array}{c}7: 10 \\
1: 0 \\
6: 6-9: 1\end{array}$ & $\begin{array}{c}6: 8 \\
1: 5 \\
4: 1-8: 5\end{array}$ & $\begin{array}{c}90.6 \\
6.5 \\
81-102\end{array}$ & $\begin{array}{c}7: 0 \\
1: 2 \\
6: 2-9: 2\end{array}$ & $\begin{array}{l}7.5 \\
3.63 \\
2-12\end{array}$ \\
\hline
\end{tabular}

\footnotetext{
a WISC-R.
} 
was presented for $500 \mathrm{msec}$ after each trial. Reaction time (RT) and error data were recorded on each trial. Incorrect responses were followed by a beep, allowing the child to utilise the auditory feedback to alter speed-accuracy trade-off. After an incorrect response, another display was presented for which the RT was not recorded to allow the child to re-focus his or her attention.

\section{Results}

Except where otherwise stated, a significance level of $p<.05$ was adopted for all statistical comparisons. Figure 2 displays average RT data as a function of the factors of the experimental design. The left panel shows the pattern of results for target present trials, in both search tasks, for both groups of children and the right panel shows RT for target absent trials. RT in the feature target condition was independent of display size for both groups. By contrast, RT in the conjunctive target condition increased linearly with display size, thus replicating previous experiments comparing RT in feature and conjunction search tasks (Duncan \& Humphries, 1989; Treisman \& Gelade, 1980; Wolfe et al., 1989). Furthermore, children with autism responded more quickly than developmentally normal children in the conjunctive condition at larger display sizes.

These data were analysed by a mixed ANOVA with one between-subjects factor of group and within-subject factors of condition (feature vs. conjunction), probe (target present vs. target absent) and display size $(5,15$, and 25). This revealed significant main effects of condition, $F(1,14)=31.24$, probe, $F(1,14)=58.03$, and display size, $F(2,28)=36.33$. Newman-Keuls pairwise comparisons showed that search times were quicker in the feature condition, slower on target absent than target present trials, and slower with larger display sizes.

There was a significant interaction between condition and display size, $F(2,28)=6.84$, confirming that an increase in display size slowed performance to a greater extent in the conjunctive condition than in the feature condition. The probe by display size interaction was also significant, $F(2,28)=12.97$, indicating that an increase in display size slowed responding to a greater extent in target absent trials than target present trials.

More importantly, there was a significant group by condition interaction, $F(1,14)=4.6$. In the feature condition, the mean RT of the control group was $165.8 \mathrm{msec}$ with a standard deviation $(S D)$ of 45.6 and that of the children with autism was $155 \mathrm{msec}(S D=63.7)$. In the conjunctive condition, the mean RT of the control group was $235 \mathrm{msec}(S D=95.9)$ while that of the group with autism was $186 \mathrm{msec}(S D=75.1)$. Simple effects analysis revealed the source of this interaction: whereas both groups responded more quickly in the feature condition $[F \mathrm{~s}(1,14)=29.9$ and 5.19 for the control group and the group with autism, respectively], there was a significant effect of group in the conjunctive condition, $F(1,20)=$
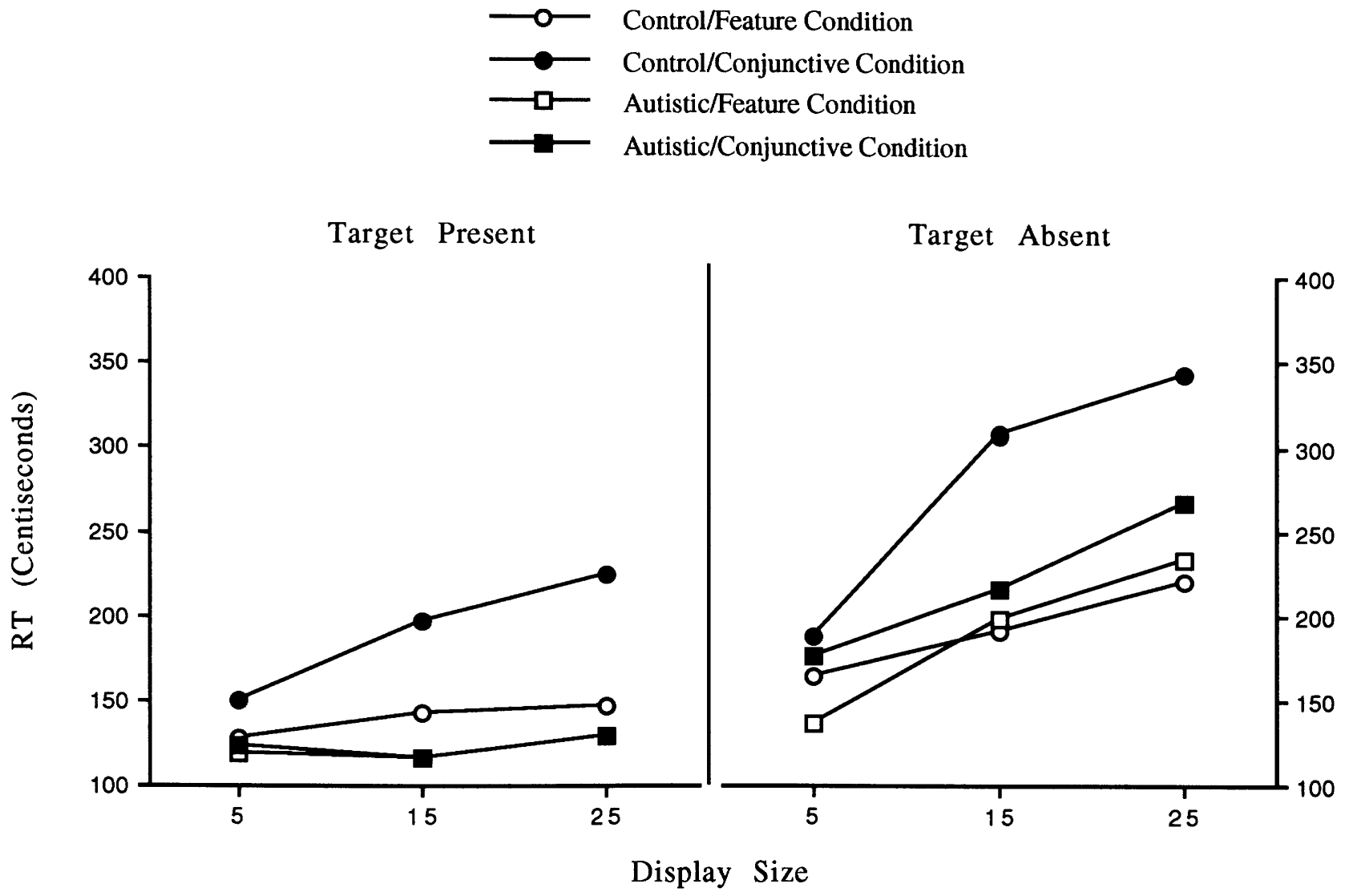

Figure 2. The reaction time scores for each group when the target was present (left panel) and absent (right panel) in the disjunctive and conjunctive conditions, when there were 5, 15, or 25 items in the display. Children with autism were faster than normal children in the conjunctive condition across the three display sizes. 
Table 2

Means and (Standard Deviations) for Each Group, in Each Condition and Display Size, Averaged across Probe Type

\begin{tabular}{lccccccc}
\hline & \multicolumn{3}{c}{$\begin{array}{c}\text { Feature condition: } \\
\text { Display size }\end{array}$} & & \multicolumn{3}{c}{$\begin{array}{c}\text { Conjunctive condition: } \\
\text { Display size }\end{array}$} \\
\cline { 2 - 4 } \cline { 6 - 7 } & 5 & 15 & 25 & & 5 & 15 & 25 \\
\hline Control & 146.5 & 166.6 & 184.2 & & 168.8 & 252.5 & 283.8 \\
& $(30.2)$ & $(25.7)$ & $(32.3)$ & & $(28.8)$ & $(57.3)$ & $(66.8)$ \\
Autism & 127.5 & 157.4 & 181.4 & & 149.7 & 190.6 & 218.3 \\
& $(26.0)$ & $(38.4)$ & $(56.1)$ & & $(41.4)$ & $(52.85)$ & $(77.0)$ \\
\hline
\end{tabular}

5.76, but not in the feature condition, $F<1$. The group with autism responded more quickly than the control group in the conjunctive condition. Finally, there was a three-way interaction between group, condition, and display size, $F(2,28)=3.25$.

In order to establish the source of this interaction, two further ANOVAs were conducted on each group's RT data, separately. These included the same within-subjects factors as before. In the analysis of the control group data, there were significant main effects of condition, $F(1,7)=19.3$, probe, $F(1,7)=20.26$, and display size, $F(2,14)=4.56$. There were also interactions between probe and display size, $F(2,14)=4.56$ and between condition and display size, $F(2,14)=9.86$. The mean RTs and SDs for each display size in each condition, averaged across probe type, for the control group are presented in the upper panel of Table 2. Simple effects analysis of the condition by display size interaction showed significant differences in RT between conditions at all three display sizes $[F \mathrm{~s}(1,7)=15.7,16.4$, and 16.27 for 5, 15, and 25 distracters, respectively], indicating that search was faster throughout in the feature condition compared to the conjunctive condition.

In the analysis of the data from the group with autism, there were also significant main effects of condition, $F(1,7)=13.2$, probe, $F(1,7)=55.3$, and display size, $F(2,14)=11.14$ and a significant interaction between probe and display size, $F(2,14)=10.6$. However, there was no interaction between condition and display size, $F<1$, showing that responding by the children with autism was as fast in the conjunctive condition as the feature condition. The mean RTs and $S D$ s for each display size in each condition, averaged across probe type, for the group with autism are presented in the lower panel of Table 2. The presence of this interaction in the control group data and its absence in the data from the children with autism therefore established the source of the threeway interaction between group, condition, and display size in the main analysis - while developmentally normal children showed a significant increase in RT with an increase in display size only in the conjunctive condition, children with autism showed a similar effect of display size in both conditions.

Error data were also analysed by ANOVA using the same factors as before. Significant main effects were obtained for group, $F(1,14)=5.21$, condition, $F(1,14)=26.84$, and probe, $F(1,14)=5.33$. The group with autism made fewer errors overall than the control group $(3.3 \%, S D=6.91$ and $6.6 \%, S D=10.23$, re- spectively), more errors were made in the conjunctive condition than in the feature condition $(7.2 \%, S D=11.2$ and $2.8 \%, S D=4.7$ respectively), and more on target present than on target absent trials $(6.66 \%, S D=10.33$ and $3.33 \%, S D=6.75$, respectively). Hence, as expected, target detection was more difficult in the conjunctive than in the feature condition. There was also an interaction between group and condition, $F(1,14)=4.93$. In the feature condition, the mean percentage errors of the control group was $4.5 \%(S D=5.2)$ and that of the children with autism was $2.1 \%(S D=4.1)$. In the conjunctive condition, the mean percentage errors of the control group was $9.8 \%(S D=12.8)$ whereas that of the group with autism was $4.6 \%(S D=8.7)$. Simple effects analysis showed that this resulted from the fact that although the groups did not differ in the number of errors made in the feature condition $F<1$, the control group made significantly more errors in the conjunctive condition compared to the group with autism, $F(1,22)=$ 9.53.

Finally, there was no evidence of a speed-accuracy trade-off in either group because error data were not correlated with RT data in either group (Pearson correlation coefficients were $r=.104$ for the group with autism and $r=.001$ for the normal group). Thus, any RT differences between groups can be taken to reflect differences in visual search rather than differences in detection criterion between groups.

\section{Discussion}

The finding that children with autism were faster than control children at detecting a conjunctive target is consistent with the idea that performance on "odd man out" tasks, or unique item detection, is enhanced in autism. This predicts that individuals with autism will show superior performance on any task that requires the individual to respond on the basis of unique cues. The study also provides an example of speeded performance in autism on an attentional measure, in contrast to many studies that show slower performance compared to control children (see Burack, Enns, Stauder, Mottron, \& Randolph, 1997, for a review).

The faster performance by children with autism in the conjunctive condition raises the possibility that enhanced performance on the embedded figures task results from the fact that it involves search for a within-dimension conjunctive target. This ostensibly stands in opposition 
to the explanation of the embedded figures task provided by the weak central coherence hypothesis (Frith, 1989; Happé, 1994). This hypothesis states that individuals with autism show a reduced ability to integrate the component features of a figure into a coherent whole. Hence, in the embedded figures task, this hypothesis suggests that the performance of normal individuals is impeded by interference from the gestalt of the picture and that this interference is greatly reduced among persons with autism. Yet, the performance of children with autism in the current conjunctive search task implies no deficit in integration of features.

Alternatively, weak central coherence might refer to a deficit in the precedence of central control processing over automatic processing. If so, the conjunctive search task used here may not tap this deficit for two reasons. First, this deficit may only become apparent in tasks that employ stimuli which produce a global gestalt as well as being composed of individual features. The search tasks used here were unlikely to have produced a global pattern since the letters were randomly placed on the screen.

Second, it has recently been shown that the linear increase in reaction time seen in such tasks can result not from the operation of control processes but from automatic processes that serve to distinguish, at an early level of analysis, the possible target from the distracters (Duncan \& Humphreys, 1989; Wolfe et al., 1989). According to these analyses, the linear increase in RT is determined by the degree to which the target and distracters are perceptually discriminable. High similarity between target and distracters therefore results in a steep RT function and low similarity results in a shallow function. This provides an explanation of the linear increase in RT in conjunctive but not feature search tasks, because the target shares more features in common overall with the total set of distracters in the conjunctive search task than it does in the feature search task. Thus, the faster RT by children with autism in the conjunctive condition observed here suggests that these automatic processes of target-distracter discrimination operate differently in autism.

A simpler way of explaining the current result is to suggest that individuals with autism show superior visuospatial skills (Shah, 1988) and that the search tasks used here and the block design, embedded figures, and discrimination tasks outlined in the Introduction tap visuospatial ability. It is certainly the case that the children with autism in this study may have had a higher spatial IQ than the developmentally normal children, because the group with autism performed significantly better on the block design test. As a preliminary check on this, we looked at the correlation between the block design scaled scores and average RTs in the conjunctive condition for each group. There was no correlation between these measures in either group $(r=.01$ for the group of children with autism and $r=.002$ for the normal group). A more thorough way of assessing this, however, would be to give the search tasks to groups of children matched on a measure of nonspatial, general IQ.

Future research is needed in order to select among these different explanations. But the present results provide an experimental demonstration of a symptom often noted in case histories of autism, namely unusually good abilities in detecting objects of interest (Kanner, 1943).

Acknowledgements - Kate Plaisted was supported by the Pinsent-Darwin Fund, University of Cambridge and a Research Fellowship from St John's College, Cambridge, and Michelle O'Riordan and Simon Baron-Cohen were supported by the MRC during the period of this work. Grateful thanks to the children who took part in this study.

\section{References}

American Psychiatric Association. (1994). Diagnostic and statistical manual of mental disorders (DSM-IV) (4th edn.). Washington, DC: Author.

Burack, J. A., Enns, J. T., Stauder, J. E. A., Mottron, L., \& Randolph, B. (1997). Attention and autism: Behavioural and electrophysiological evidence. In D. J. Cohen \& F. R. Volkmar (Eds.), Autism and pervasive developmental disorders: A handbook. New York: Wiley.

Courchesne, E., Townsend, J., Ashoomoff, N. A., YeungCourchesne, R., Press, G., Murakami, J., Lincoln, A., James, H., Saitoh, O., Haas, R., \& Schreibman, L. (1994). A new finding in autism: Impairment in shifting attention. In S. H. Broman \& J. Grafman (Eds.), Atypical cognitive deficits in developmental disorders: Implications for brain function (pp. 101-137). Hillsdale, NJ: Lawrence Erlbaum.

Courchesne, E., Townsend, J., Ashoomoff, N. A., Saitoh, O., Yeung-Courchesne, R., Lincoln, A., James, H., Haas, R., Schreibman, L. A., \& Lau, L. (1994). Impairment in shifting attention in autistic and cerebellar patients. Behavioural Neuroscience, 108, 848-865.

Duncan, J., \& Humphreys, G. (1989). Visual search and stimulus similarity. Psychological Review, 96, 433-458.

Dunn, L. M., Dunn, L. M., Whetton, C., \& Pintile, D. (1982). British Picture Vocabulary Scale. London: NFER-Nelson.

Frith, U. (1989). Autism: Explaining the enigma. Oxford: Blackwell.

Gerhardstein, P. (1997). Reaction-time measures of visual search at 1,2 and 3 years of age. Poster presented at the Annual Conference of the Society for Research in Child Development, Washington, DC.

Happé, F. G. E. (1994). Autism: An introduction to psychological theory. London: UCL Press.

Hayes, R. (1987). Training for work. In D. J. Cohen \& A. M. Donnellan (Eds.), Handbook of autism and pervasive developmental disorders. Silver Springs, MD: Winston.

Jolliffe, T., \& Baron-Cohen, S. (1997). Are people with autism and Asperger syndrome faster than normal on the Embedded Figures Test? Journal of Child Psychology and Psychiatry, 38, $527-534$.

Kanner, L. (1943). Autistic disturbances of affective contact. Nervous Child, 2, 217-250.

National Society for Autistic Children. (1978). National Society for Autistic Children: Definition of the syndrome of autism. Journal of Autism and Developmental Disorders, 8, 162-167.

Plaisted, K. C., O'Riordan, M. A. F., \& Baron-Cohen, S. (1998). Enhanced discrimination of novel, highly similar stimuli by adults with autism during a perceptual learning task. Journal of Child Psychology and Psychiatry, 39, 765-775.

Posner, M. I. (1980). Orienting of attention. Quarterly Journal of Experimental Psychology, 32, 3-25.

Shah, A. (1988). Visuospatial islets of ability and intellectual functioning in autism. Unpublished $\mathrm{PhD}$ thesis, University of London.

Shah, A., \& Frith, U. (1983). An islet of ability in autistic children: A research note. Journal of Child Psychology and Psychiatry, 24, 613-620. 
Shah, A., \& Frith, U. (1993). Why do autistic individuals show superior performance on the block design task? Journal of Child Psychology and Psychiatry, 34, 1351-1364.

Townsend, J., Courchesne, E., \& Egaas, B. (1996). Slowed orienting of covert visual-spatial attention in autism: Specific deficits associated with cerebellar and parietal abnormality. Development and Psychopathology, 8, 563-584.

Triesman, A., \& Gelade, G. (1980). A feature integration theory of attention. Cognitive Psychology, 12, 97-136.

Wainwright, J. A., \& Bryson, S. E. (1996). Visual-spatial orienting in autism. Journal of Autism and Developmental Disorders, 26, 423-438.
Wainwright-Sharpe, J. A., \& Bryson, S. E. (1993). Visual orienting deficits in high-functioning people with autism. Journal of Autism and Developmental Disorders, 23, 1-13.

Wechsler, D. (1976). The Wechsler Intelligence Scale for Children-Revised. New York: Psychological Corporation.

Wolfe, J. M., Cave, K. R., \& Franzel, S. L. (1989). Guided search: An alternative to the feature integration model for visual search. Journal of Experimental Psychology: Human Perception and Performance, 15, 419-433.

Manuscript accepted 12 September 1997 
Copyright $\odot 2003$ EBSCO Publishing 